and 53.5 percent of those under age 25 have never worked. From this point of view, it is not surprising that students are looking for education and work opportunities abroad that will help them find a job once back in Spain.

Even though the economy and the employment situation in Spain have not improved in the last few years, ERASMUS applications have remained stable or even grown. In other words, ERASMUS mobility has been consolidated as part of the Spanish curriculum despite economic difficulties and unemployment. These are the two key reasons that motivate Spanish students to join the ERASMUS program, whose main purpose is seen as a means to improve graduate employability.

\section{When is an International Branch Campus?}

\section{Nigel Healy}

Nigel Healey is professor and pro-vice-chancellor (International) at Nottingham Trent University, UK. E-mail:nigel.healey@ntu.ac.uk.

For or a Nottingham alumnus, driving onto the University - of Nottingham's branch campus in Malaysia is a surreal experience. Surrounded by tropical rainforest, a familiar white silhouette emerges - a clock tower atop the signature Trent Building, overlooking a large lake. Despite the heat and humidity, the campus at Semenyih looks and feels like an extension of the University of Nottingham, reinforcing its "one university, three campuses" (United Kingdom, Malaysia and China) branding.

\section{Defining International Branch Campuses}

In 2009, the Observatory for Borderless Higher Education (OBHE) famously defined an international branch campus as "an offshore operation of a higher education institution which meets the following criteria":

- "The unit should be operated by the institution or through a joint venture in which the institution is a partner...in the name of the foreign institution and

- upon successful completion of the course program, which is fully taken at the unit abroad, students are awarded a degree from the foreign institution."

This definition is widely cited and remains useful. Certainly, the Semenyih campus meets the criteria: the unit is operated as a joint venture between the University of Nottingham and two Malaysia property companies, Boustead and YTL; it is branded as University of Nottingham Malaysia Campus (UNMC); and the students graduate with a University of Nottingham degree.

OBHE's American counterpart, the Cross-Border Education Research Team (C-BERT) at the State University of New York at Albany, similarly defines an international branch campus as "an entity that is owned, at least in part, by a foreign education provider; operated in the name of the foreign education provider; engages in at least some faceto-face teaching; and provides access to an entire academic program that leads to a credential awarded by the foreign education provider."

\section{Changing Conditions and Environments}

A closer look at the 200 or so international branch campuses being monitored by the OBHE and C-BERT reveals that, as Jason Lane and Kevin Kinser noted in their cleverly titled article ("One definition to rule them all"), getting a clear definition "is a fairly slippery subject." In its 20 I2 report on international branch campuses, the OBHE acknowledged the impracticality of having a "permanent definition," because universities are constantly repositioning their offshore activities in the light of changing regulatory and competitive environments.

To illustrate the difficulty of defining an international branch campus, take the University of Nottingham's Malaysia Campus (UNMC) as an example. The "campus" is legally incorporated as a private Malaysian company, in which the two local partners have the majority stake. The University of Nottingham is, in effect, the minority shareholder in a private offshore company. With the exception of the senior managers, who are seconded from Nottingham, the faculty and staff are employed by the Malaysian company and managed by one of the Malaysian partner's human resources department on local terms and conditions.

UNMC is, from the perspective of the host Ministry of Education-a Malaysian private higher education institution. It is subject to oversight by the ministry, which approves its tuition fees and enrollments. Its curriculum is accredited by the Malaysian Qualifications Agency and the qualifications offered must fit within the Malaysian Qualifications Framework.

Viewed in terms of its key stakeholders, UNMC begins to look less like a UK transplant than the clock tower and the architecture of the buildings suggest. The majority shareholders are Malaysian. Most of the faculty and staff are Malaysian, and all but a handful of seconded managers are locally employed. The students, the regulators, and the companies that employ most of the graduates are all Malaysian. 


\section{Evolving Relationships with the Home Campus}

Does the fact that the company trades under the University of Nottingham brand and awards its degrees tie it inexorably to the United Kingdom and ensure its status as an international branch campus? In principle, both defining features could be swept away at a pen stroke. Like Middlesex and Heriot-Watt, the University of Wollongong operates a "branch campus" in Dubai. The UK universities offer degrees from the home campus under a license from Dubai's Knowledge and Human Development Agency. In contrast, Wollongong initially set up its campus as the Institute of Australian Studies and, since 2004, the University of Wollongong in Dubai has been licensed by the federal government of the United Arab Emirates as an independent, private institution awarding local, not Australian, degrees.

\section{Branch campuses start as dependent in- fants, but as they begin to develop their own personalities the bonds with their mother inevitably weaken until they are broken for good.}

In conversation with faculty at international branch campuses, one of the most widely used metaphors is that of a child-parent relationship. Branch campuses start as dependent infants, reliant on the mother university for their every need. As they grow and mature, they become unruly teenagers, chafing at parental control and striving for greater autonomy. As young adults, they begin to develop their own personalities and the bonds with their mother inevitably weaken until they are broken for good.

The University of London, which nurtured constituent colleges around the world, can today claim, inter alia, the University of Zimbabwe, the University of the West Indies, and the University of Peradeniya (Sri Lanka) as its estranged, grown-up children. Ironically, like the Universities of Leicester and Southampton, the University of Nottingham also started life as a college of the University of London. In the United Kingdom, the country's 45 polytechnics operated under the control of the Council for National Academic Awards, which validated their curricula and awarded their degrees. This nation-wide experiment in regional branch campuses ended in I992, when the polytechnics were restructured into independent, degree-awarding universities.

Returning to UNMC, despite its strong Malaysian identity, there is no suggestion that it is ready to sever its ties to the mother campus. The reason is that its current status as a branch campus gives it a valuable competitive advantage in the Southeast Asian market. As part of the University of Nottingham, it can claim a global ranking of 75th in the world (according to the QS World University Rankings 20I3-20I4) and a history that dates back to I88I. The commonality of the Nottingham-based and Malaysianbased curriculum guarantees students an internationally portable degree, while the exchange of leading research scientists and PhD students has accelerated the creation of an academic culture on the Malaysian campus.

UNMC is likely to remain a branch campus for as long as the reputational benefits of a close association with the mother campus outweigh the costs in terms of constraining its ability to adapt to local conditions. In an intensely competitive and sophisticated region like Southeast Asia, these benefits are likely to dominate for a number of years. In other markets, notably China where the Ministry of Education views Sino-foreign joint ventures as private Chinese institutions, the lead time to full independence may be shorter. In all host countries, higher education is regulated and policymakers - as in Zimbabwe, the West Indies, and Sri Lanka in the past-may take their own view about how long they are willing to accept foreign universities controlling parts of their educational sectors.

\section{Asking a Different Question}

Answering the question "what is an international branch campus?" is fraught with difficulty. Different branch campuses have very different degrees of localization of the key stakeholders - notably, the owners, the managers, the faculty and staff, the curriculum, the accreditation, and the branding-and these boundaries blur in response to the strategies of the home universities and the requirements of the host market.

Perhaps the more interesting question is "when is a branch campus?" In other words, at what point are the organizational ties between the mother university and the branch campus strong enough to meaningfully regard one as the subsidiary of the other? An educational institution will choose to position itself as the branch campus of a more powerful foreign university for as long as the reputational and competitive benefits of this association outweigh the benefits of independence. How long this lasts may vary from country to country, but history suggests that international branch campuses either flourish and become independent, or fail and close. No one remains a child forever. 